\title{
Synthesis of Carbon Nanostructures by Using Thermal Plasma Torch
}

\author{
M. Pacheco ${ }^{1}$ J. Pacheco ${ }^{1,2, *}$, M. Valdivia ${ }^{2}$, L. Bernal $^{2}$, R. Valdivia ${ }^{2}$, \\ A. Huczko ${ }^{3}$, H. Lange ${ }^{3}$, A. Cruz $^{1}$, and R. López-Callejas ${ }^{1,2}$ \\ ${ }^{1}$ Instituto Nacional de Investigaciones Nucleares, Apartado Postal 18-1027, Col. Escandón, \\ C.P. 11801, México D.F., México \\ ${ }^{2}$ Instituto Tecnologico de Toluca, Apartado Postal 890, Toluca, México \\ ${ }^{3}$ Department of Chemistry, Warsaw University, Pasteur 1, 02-093 Warsaw, Poland \\ *jps@nuclear.inin.mx
}

Received on 30 January, 2004; revised version received on 6 May, 2004

\begin{abstract}
Some recent results concerning the synthesis of carbon nanostructures in a thermal plasma generating by a plasma torch are presented. Several tests were carried out in different operational conditions. The plasma was formed with argon and different gas mixtures of argon-acetylene or argon-methane to which some catalyst materials (ferrocene and cerium oxide) were added. These catalysts were introduced into the plasma in a solid (powder) or/and a gaseous state. Their feeding rate into the plasma jet was fixed along with some other operating conditions such as plasma power, gas flow rate and reactor pressure. The principal main feature observed was a short reaction time so that each test lasted for no longer than 5 minutes. The solid products obtained were collected and prepared for following analyses. The products were examined using XRD and TEM techniques in order to characterize the morphological structure of their samples. The spatial distribution of temperature in the plasma was evaluated by in-situ emission spectroscopy. The self-absorption was taken into account by simulating an integrated radiation in relation to the Swan band $d^{3} \Pi g \longrightarrow \mathrm{a}^{3} \Pi u(0,0)$, emitted by the $\mathrm{C}_{2}$ radical. Also, the exhaust gases were characterized by gas chromatography during each test.
\end{abstract}

\section{Introduction}

Since their discovery in 1991 [1], carbon nanotubes (CNTs) have been immediately recognized by the whole scientific community as a new material with unique mechanical and electronic properties. The controlled production of CNTs could open the way to vast applications. In fact, the uses of carbon nanostructures are numerous and increase day after day. Among their potential applications, one can mention hydrogen storage, the reinforcement of composites with ceramic and polymer matrices, the development of specialized lamps and flat panels, etc. [2-5].

There exist several techniques of nanocarbon production, and particularly of carbon nanotubes. The laser ablation [6-10] and the electric arc [11-13] are considered to be among the best, due to a relatively high yield of nanotubes with few defects in their structure, in comparison with the product synthesized by, for instance, the catalytic vapor deposition (CVD) technique [14]. However, the cost of producing carbon nanostructures still remains high, mostly because the first two processes mentioned above are neither continuous nor scalable. Thus, new methods to synthesize different nanocarbons are urgently sought after. The aim of this work has been to produce carbon nanostructures in a thermal plasma jet using a plasma torch, where gases (methane, acetylene) or liquids (benzene) rich in carbon, as well as some catalysts (ferrocene, nickel, yttrium) necessary for the nanostructure growth are continuously fed.

D. Harbec et al $[15,16]$ use a plasma torch technique with $C_{2} C l_{4}$ as a carbon precursor and a very high power supply $(100 \mathrm{~kW})$. Nevertheless, the nanotube production rates remain low. H. Takikawa et al [17] have proposed a torch arc in open air in order to produce carbon nanotubes and nanohorns. The carbon yield in the deposit seems to be considerably lower than that in the soot, prepared in a conventional low-pressure arc.

In the present paper we report a study on the plasma torch parameters, the nature of catalysts and the characterization (XRD, TEM) and formation of carbon nanostructures. The knowledge of the basic plasma phenomena and their effect on the nanostructure formation has been rather limited so far. Thus, we have also decided to characterize the plasma by emission spectroscopy in order to determine whether the results could be related to the variations in plasma characteristics such as temperature and their effect on the type of nanostructure.

\section{Experimental}

In all the experiments described below, the plasma was generated by a DC plasma torch with a $10 \mathrm{~kW}$ power maximum output. The pressure in the reactor could be controlled within a $10-100 \mathrm{kPa}$ range by means of a pumping system 
TABLE 1. Characteristics of reactants and process features

\begin{tabular}{|c||c|l|}
\hline Gas & Catalist(s) & Observations \\
\hline \hline None & $\left(C_{5} H_{5}\right)_{2} \mathrm{Fe}(2.93 \mathrm{~g})$ & Only ferrocene was introduced into the plasma \\
\hline $\mathrm{CH}_{4}(0.941)$ & $\left(C_{5} \mathrm{H}_{5}\right)_{2} \mathrm{Fe}(1.96 \mathrm{~g})$ & $\begin{array}{l}\text { A great quantity of soot obtained, but the powder feeding was not } \\
\text { continuous }\end{array}$ \\
\hline $\mathrm{C}_{2} \mathrm{H}_{2}(0.51)$ & $\left(\mathrm{C}_{5} \mathrm{H}_{5}\right)_{2} \mathrm{Fe}(1.16 \mathrm{~g})$ & $\begin{array}{l}\text { More soot was obtained vis--vis the conditions mentioned before; } \\
\text { powder feeding still presents the same problem }\end{array}$ \\
\hline $\mathrm{C}_{2} \mathrm{H}_{2}(0.121)$ & $\mathrm{Ni}+\mathrm{CeO}_{2}(0.07 \mathrm{~g})$ & $\begin{array}{l}\text { The mixture of nickel and cerium oxide promotes the carbon nano- } \\
\text { tubes production in the electric arc technique }\end{array}$ \\
\hline
\end{tabular}

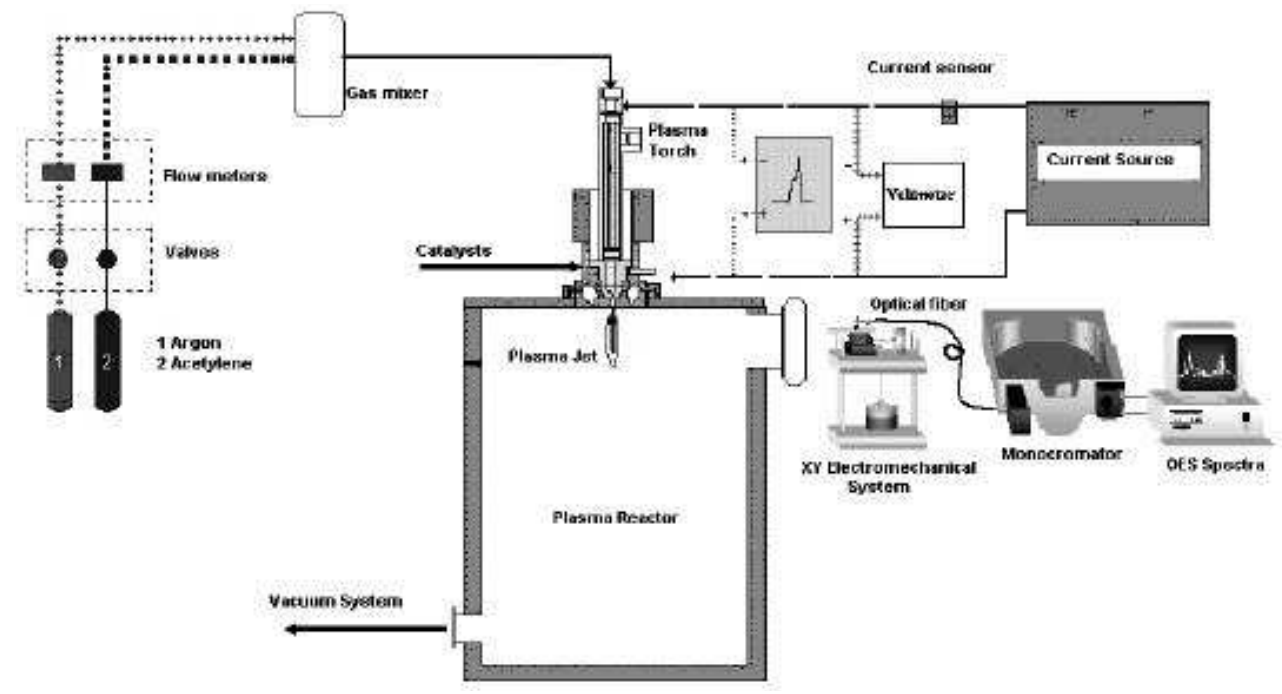

Figure 1. Plasma reactor.

and a special valve. The DC current can be adjusted from 60 up to 150 A. The plasma reactor (Fig. 1) was also provided with a special port intended for OES measurements. The radiation emitted by the plasma was focused by a convergent lens towards the entry slit of the $320 \mathrm{~mm}$ focal length monochromator endowed with a 1800 grooves/mm holographic grating and a CCD detector (122 x 1024 pixels). The general spatial resolution turned out to be $0.06 \mathrm{~nm}$. The spectra for different intensity ranges and wavelengths could be obtained by means of some ad hoc software [18]. The optical signal of the plasma was guided by an optic fiber mounted on a XY electromechanical system [19] so to achieve a vertical and horizontal scanning of the plasma with very precise incremental steps $(0.1 \mathrm{~mm})$.

All the experiments were performed under stable operational conditions at an $80 \mathrm{~A}$ arc current. Argon was used as a plasma gas with $100 \mathrm{kPa}$ pressure and a $15 \mathrm{l} / \mathrm{min}$ flow rate. Different mixtures of reactants (as shown in Table 1) containing gases (methane or acetylene) and catalysts (ferrocene, cerium oxide and nickel) were introduced into the argon plasma. Feed rates of catalysts and hydrocarbon gas were maintained constant at about $0.1 \mathrm{~g} / \mathrm{min}$ and $0.1 \mathrm{1} / \mathrm{min}$ respectively.

\section{Results and discussion}

Optical emission spectroscopy (OES) technique was used to determine the excitation and rotation temperatures in terms of atomic lines (ArI) and rotational lines $\left(C_{2}\right.$ Swan band). These temperatures have already been discussed within the frame of nanocarbon morphology. The solid products were analyzed by high resolution transmission electron (HTEM), and scanning electron microscopy (SEM). The XRD technique completed this study by determining whether the structure of the product was either amorphous or crystalline. In order to measure the quantity of carbon leaving the reactor, the exhaust gases were characterized by gas chromatography during each test.

\subsection{OES Measurements}

OES is one of the most employed diagnostics techniques intended to characterize the chemical species participating in the plasma. The information gathered can be processed so to deduce the temperature distribution. Spectroscopic investigation was performed using the facilities described in the preceding section. In order to ensure reliable information, several measurements in different locations in the plasma 
were carried out within a $640 \mathrm{~ms}$ integration time of the detection system.

\subsection{Rotational temperature}

The optical radiation from a plasma containing carbon is mainly associated with the Swan band system, $\mathrm{d}^{3} \Pi \mathrm{g} \longrightarrow$ $\mathrm{a}^{3} \Pi \mathrm{u}(0,0)$, emitted by $\mathrm{C}_{2}$ radicals. The band is often affected by the self absorption phenomenon, particularly under conditions favoring carbon nanostructures (dense carbon vapors). The self-absorption influencing the intensity distribution in the rotational structure has often been used for temperature evaluation. The method is explained in detail elsewhere [20-22]. The $\mathrm{C}_{2}$ Swan band is located from 513.1 to $516.3 \mathrm{~nm}$ wavelengths. The maximal values are obtained at the central axis. The radial scan of the $5 \mathrm{~mm}$ diameter plasma jet was obtained during the catalyst injection. This scan was performed at $10 \mathrm{~mm}$ from the torch nozzle, where the maximal intensities of $\mathrm{C}_{2}$ radicals were located.

\subsection{Temperature of excitation}

When pure argon is used as a plasma gas, the Boltzmann diagram method can be applied in order to calculate the temperature, based on several lines $(430.01 \mathrm{~nm}, 675.28 \mathrm{~nm}$, $696.5 \mathrm{~nm}, 706.72 \mathrm{~nm}, 727.29 \mathrm{~nm}$ ). We report in figure 2, both the rotational (for hydrocarbons-catalysts mixtures) and the excitation (for pure $\mathrm{Ar}$ and $\mathrm{Ar}-\mathrm{CH}_{4}$ ) temperatures found in the $z$ axis plasma jet. Such temperatures were obtained for a mixture of $\mathrm{Ar}-\mathrm{CH}_{4}$. We can assume the existence of a local thermodynamic equilibrium at $z<1 \mathrm{~cm}$ (figure 2 ) as the temperatures of rotation and excitation remain very close (less than 3\%).

In Fig. 2, we can observe that temperature gradients are smaller when ferrocene and methane/ferrocene are present in the plasma. A temperature decrease and drastic temperature profiles are observed when $\mathrm{C}_{2} \mathrm{H}_{2}$ are introduced. In this case, higher quantities of soot are produced (for equal experimental times) while the amount of nanostructures is almost non existent. Instead, amorphous carbon (AC) and poorly organized polyaromatic amorphous carbon (POPAC) are the predominant structures, as we will see below.

\subsection{XRD and TEM analysis}

The XRD analysis was performed to determine whether crystalline phases exist in the samples. By comparing results from XRD and TEM (Fig. 3) we can observe that an XRD rich spectra correspond to a well organized carbon nanostructure (Figs. 3a, 3c, 3e), whereas a spectra with no lines signifies that carbon nanostructures are almost absent in the sample (Fig. 3g).

Results from TEM (Figs. 3d, 3f, 3h) show that synthesis of multiwalled nanotubes becomes characteristic when only ferrocene is added (Fig. 3b). When ferrocene and methane are used, the formation of multiwalled nanocapsules is enhanced (Fig. 3d). When acetylene and ferrocene are added, only a few nanocapsules are obtained (Fig. 3f) and, in the case of acetylene and nickel with cerium oxide, no nanostructures were found.

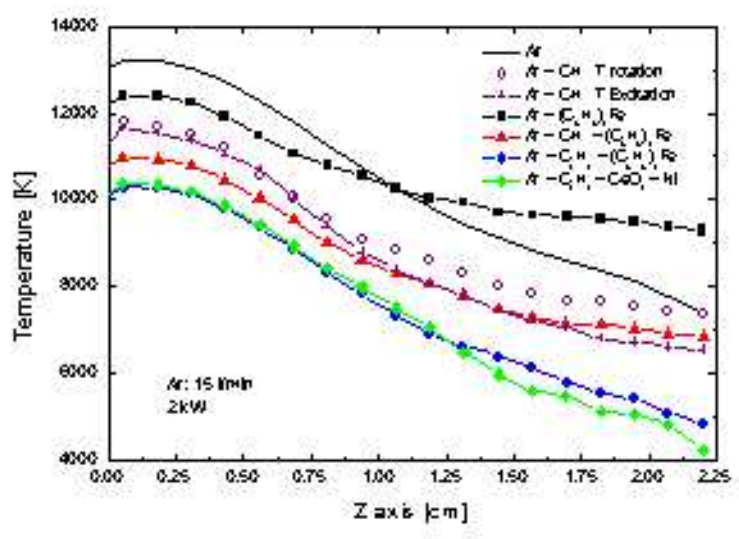

Figure 2. Temperature profiles.

\subsection{Gas Chromatography analysis}

Exhaust gas chromatography analyses were performed for each experimental condition in order to determine the quantity and composition of these gases. The results provided valuable information about the mass balance and helped verify the quantity of $\mathrm{C}$ that remained in the reactor (Table 2). By correlating these results with the nanostructures obtained, we can show that the nanostructures have been preferably formed when the ratio carbon/catalysts was about $91.5 \%$ at $/ 8.5 \%$ at.

TABLE 2. Carbon and catalysts concentration in the produced soot

\begin{tabular}{|c||c|c|}
\hline Mixture & Carbon \% at & Catalyst \% at \\
\hline$A r+\left(C_{5} H_{5}\right)_{2} F e$ & 91.3 & 8.7 \\
\hline$A r+\mathrm{CH}_{4}+\left(\mathrm{C}_{5} \mathrm{H}_{5}\right)_{2} \mathrm{Fe}$ & 91.7 & 8.3 \\
\hline $\mathrm{Ar}+\mathrm{C}_{2} \mathrm{H}_{2}+\left(\mathrm{C}_{5} \mathrm{H}_{5}\right)_{2} \mathrm{Fe}$ & 93.04 & 6.96 \\
\hline $\mathrm{Ar}+\mathrm{C}_{2} \mathrm{H}_{2}+\mathrm{CeO}_{2}+\mathrm{Ni}$ & 97.62 & 2.38 \\
\hline
\end{tabular}

\section{Conclusions}

It is found that carbon nanostructures were best formed when the atomic ratio carbon/catalysts was about $91.5 \%$ at / 8.5\% at. Also the plasma, under such conditions, became more uniform. Apparently by diminishing temperature gradients in the plasma and using the above mentioned ratio carbon/catalysts, the synthesis of carbon nanostructures turned to be more efficient $\left(\mathrm{Ar}+\left(\mathrm{C}_{5} \mathrm{H}_{5}\right) \mathrm{Fe}\right.$ and $\mathrm{Ar}+\mathrm{CH}_{4}+$ $\left.\left(\mathrm{C}_{5} \mathrm{H}_{5}\right) \mathrm{Fe}\right)$. Similar results were obtained by using an electric arc, where smaller temperature gradients correspond to the best production of carbon nanotubes for different experimental conditions [23]. More experiments maintaining the same $(91.5 \%$ carbon $) /(8.5 \%$ catalyst $)$ ratio with acetylene are still called for to correlate temperature gradients with the carbon nanostructure yield. 
XRD

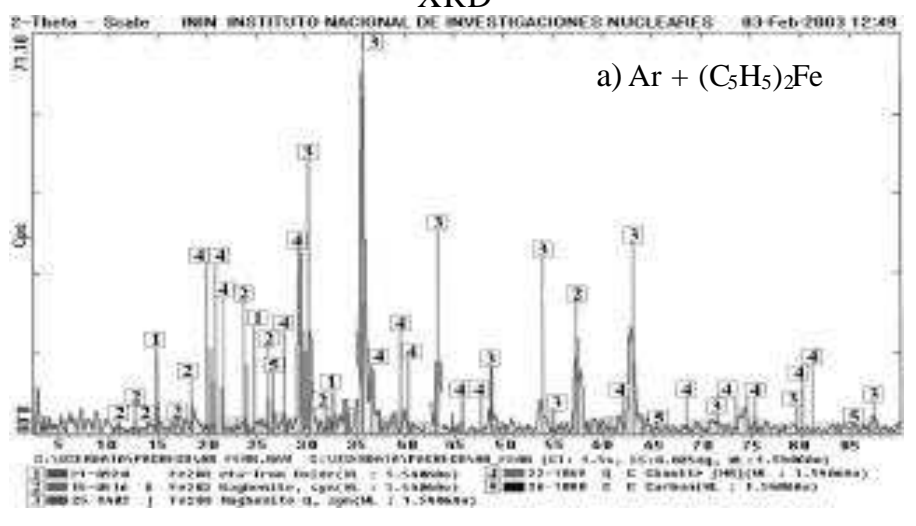

TEM
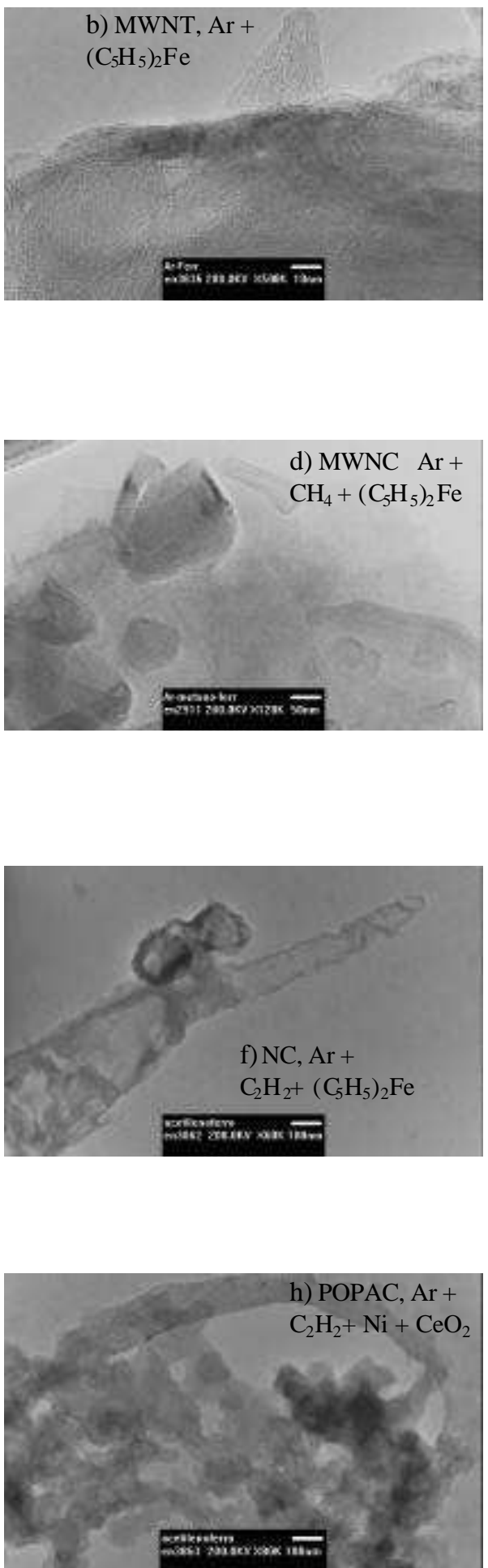

Figure 3. XRD and TEM results: a) and b) $\mathrm{Ar}+\left(\mathrm{C}_{5} \mathrm{H}_{5}\right)_{2} \mathrm{Fe}$; c) and d) $\mathrm{Ar}+\mathrm{CH}_{4}+\left(\mathrm{C}_{5} \mathrm{H}_{5}\right)_{2} \mathrm{Fe}$; e) and f) $\mathrm{Ar}+\mathrm{C}_{2} \mathrm{H}_{2}+\left(\mathrm{C}_{5} \mathrm{H}_{5}\right)_{2} \mathrm{Fe}$; g) and h) $\mathrm{Ar}+\mathrm{C}_{2} \mathrm{H}_{2}+\mathrm{Ni}+\mathrm{CeO}_{2}$. Abbreviations: MWNT - multiwalled nanotube; $\mathrm{MWNC}-$ multiwalled nanocapsule; POPAC - poorly organized polyaromatic amorphous carbon; AC - amorphous carbon. 


\section{Acknowledgements}

The supports obtained from CONACyT (contract 33424-U), ECOS/ANUIES (contract MOO-P04), and COSNET (contracts 619.02PR and 630.03) are gratefully acknowledged. The study was partially supported by the Committee for Scientific Research (KBN) through the Department of Chemistry, Warsaw University, under contract 4 T08D 02123.

\section{References}

[1] S. Iijima, Nature 354, 54 (1991).

[2] L. Allemand, La Recherche 332, 55 (2000).

[3] A. Chatelain, J. M Bonnard, Le Temps stratégique 81, Genève, (mai-juin 1998).

[4] P. Collins, P. Avouris, Pour la Science 280, 76 (2001).

[5] P. Poncharal et al. Science, 283, 1513 (1999). cité á La recherche 320, 19 (1999).

[6] T. Guo, P. Nikolaev, A. G. Rinzler, D. Tomanek, D.T. Colbert, and R. E. Smalley, J. Phys. Chem. 99, 10694 (1995).

[7] T. Guo, P. Nikolaev, A. Thess, D. T. Colbert, and R. E. Smalley, Chem. Phys. Lett. 243, 49 (1995).

[8] A. Thess, R. Lee, P. Nicolaev, H . Dai, P. Petit, J. Robert, C. Xu, Y. H. Lee, S. G. Kim, D. T. Colbert, G. Scuseria, D. Tomanek, J. E. Fischer, and R. E. Smalley, Science 273, 487 (1996)

[9] W. K. Masser, E. Munoz, A. M. Benito, M. T. Martinez, G. F. de la Fuente, A. Righi, and J. L. Sauvagol, Chem. Phys. Lett, 292, 587 (1998).

[10] A. G. Rinzler, J. Liu, H. Dai, P. Nikolaev, C. B. Huffman, F. J. Rodriguez-Macias. P. J. Boul, A. H. Lu, D. Heymann, D. T. Colbert, R. E. Smalley, S. J. Tans, and C. Dekker, Nature 385, 781 (1997).

[11] C. Journet, W. K. Maser, P. Bernier, A. Loiseau M. Lamy de la Chapelle, S. Lefrant, P. Deniard, R. Lee, and J. E. Fisher, Nature, 388, 756 (1997).

[12] M. Pacheco, M. Monthioux, M. Caprais, H. Allouche, M. Razafinimanana, and A. Gleizes "New data about the formation of SWNTs by the electric arc method" XVIth International Winterschool on Electronic Properties of Novel Materials, 29 mars 2002, Kirchberg.
[13] M. Pacheco, M. Monthioux, H. Allouche, M. Razafinimanana, A. Gleizes, and N. Caprais, "New factors controlling the formation of single-wall carbon nanotubes by arc plasma", CARBON 2002, 15-20, September 2002, Beijing.

[14] M. J. Yacaman, M. M. Yoshida, L. Rendon, and J. G. Santiesteban, Appl. Phys. Lett. 62, 202 (1993).

[15] D. Harbec, J.-L. Meunier, L. Guo, and R. Gauvin, 15th International Symposium on Plasma Chemistry, Orleans France, pp 2757-2762, (9-13 July 2001).

[16] D. Harbec, J.-L. Meunier, and U. S. Patent Appl. Number 60/426, 407 (2002).

[17] H. Takikawa,, M. Ikeda, K. Hirahara, Y. Hibi, Y. Tao, P. A. Ruiz Jr., T. Sakakibara, S. Itoh, and S. Iijima, Physica B 323, 277 (2002).

[18] SA1400, Hamamatsu software for card and program SA1400, Version 3.0 (1999).

[19] Joel Martínez Adame, "Determination of spectral lines of $\mathrm{H}_{2}$ and $\mathrm{C}$ by using CCD detector", Electronic Engineering Thesis, Instituto Tecnológico de Toluca, Mexico, (2002).

[20] H. Lange, A. Huczko, M. Sioda, M. Pacheco, M. Razafinimanana, and A. Gleizes "On self absorption method for determination of $\mathrm{C}_{2}$ in carbon ac plasma". Progress in Plasma Processing of Materials, P. Fauchais editeur, Begell House Inc. (2002).

[21] M. Pacheco, M. Monthioux, M. Caprais, H. Allouche, M. Razafinimanana, and A. Gleizes, (2002) "New data about the formation of SWNTs by the electric arc method" XVIth International Winterschool on Electronic Properties of Novel Materials, Kirchberg, (2-9 mars 2002).

[22] M. Razafinimanana, M. Pacheco, M. Monthioux, H. Allouche, H. Lange, A. Huczko, and A. Gleizes, (2001) "Spectroscopic study of an electric arc with Gd and Fe doped anodes for the carbon nanotube formation". 25th International Conference on Phenomena in Ionized Gases, Extend. Abstr. 3, pp. 297-298, Nagoya, Japan (17-22 July, 2001).

[23] Marquidia Pacheco "Synthèse des nanotubes de carbone par arc electrique". PhD Thesis, Université Paul Sabatier, Toulouse, France (2003). 